\title{
Household antimicrobial self-medication: a systematic review and meta-analysis of the burden, risk factors and outcomes in developing countries
}

\author{
Moses Ocan ${ }^{1 *}$, Ekwaro A. Obuku ${ }^{2,6}$, Freddie Bwanga ${ }^{3}$, Dickens Akena ${ }^{4}$, Sennono Richard ${ }^{5}$, \\ Jasper Ogwal-Okeng ${ }^{1}$ and Celestino Obua ${ }^{1}$
}

\begin{abstract}
Background: Antimicrobial self-medication is common in most low and middle income countries (LMICs). However there has been no systematic review on non-prescription antimicrobial use in these settings. This review thus intended to establish the burden, risk factors and effects of antimicrobial self-medication in Low and Middle Income Countries.

Methods: In 2012, we registered a systematic review protocol in PROSPERO (CRD42012002508). We searched PubMed, Medline, Scopus, and Embase databases using the following terms; "self-medication", "non-prescription", 'self-treatment', "antimicrobial", "antimalarial", "antibiotic", "antibacterial" "2002-2012" and combining them using Boolean operators. We performed independent and duplicate screening and abstraction of study administrative data, prevalence, determinants, type of antimicrobial agent, source, disease conditions, inappropriate use, drug adverse events and clinical outcomes of antibiotic self-medication where possible. We performed a Random Effects Meta-analysis.
\end{abstract}

Results: A total of thirty four (34) studies involving 31,340 participants were included in the review. The overall prevalence of antimicrobial self-medication was $38.8 \%$ (95 \% Cl: 29.5-48.1). Most studies assessed non-prescription use of antibacterial (17/34: $50 \%$ ) and antimalarial (5/34: $14.7 \%)$ agents. The common disease symptoms managed were, respiratory (50\%), fever (47\%) and gastrointestinal (45\%). The major sources of antimicrobials included, pharmacies (65.5\%), leftover drugs (50 \%) and drug shops (37.5\%). Twelve (12) studies reported inappropriate drug use; not completing dose (6/12) and sharing of medicines (4/12). The main determinants of antimicrobial self-medication include, level of education, age, gender, past successful use, severity of illness and income. Reported negative outcomes of antimicrobial self-medication included, allergies (2/34: $5.9 \%$ ), lack of cure (4/34: 11.8 \%) and causing death (2/34: $5.9 \%)$. The commonly reported positive outcome was recovery from illness (4/34: $11.8 \%$ ).

Conclusion: The prevalence of antimicrobial self-medication is high and varies in different communities as well as by social determinants of health and is frequently associated with inappropriate drug use.

\section{Background}

Self-medication refers to the use of medicines to treat self-diagnosed disorders without consulting a medical practitioner and without any medical supervision [1]. It is a common form of healthcare practiced in most parts of the world, with over $50 \%$ of antibiotics purchased and used over-the-counter [2,3]. Inadequacies in the healthcare delivery systems especially in resource limited countries such as inequitable distribution, high costs,

\footnotetext{
* Correspondence: mss_ocan@yahoo.co.uk

'Department of Pharmacology \& Therapeutics, College of Health Sciences, Makerere University, P.O. Box 7072, Kampala, Uganda

Full list of author information is available at the end of the article
}

inaccessibility, lack of health care professionals, unregulated distribution of medicines, patient attitudes towards physicians are some of the key drivers of self-medication $[4,5]$.

Non-prescription use of antimicrobial drugs is associated with the risk of inappropriate drug use which predisposes patients to drug interactions, masking symptoms of underlying disease and development of microbial resistance [4, 6-8]. The inappropriate drug use practices common in self-medication include; short duration of treatment, inadequate dose, sharing of medicines and stopping treatment upon improvement of disease symptoms [9]. Resistance to the available and affordable antimicrobial agents may further reduce the already limited therapeutic choices in 
treatment of common infectious diseases in developing countries, increasing the risk of morbidity and mortality [6].

In resource limited countries, the overall extent and determinants of self-medication with antimicrobial agents is difficult to quantify especially due to lack of monitoring and record keeping [10]. In addition the findings of studies on antimicrobial self-medication in these settings have not been consistent for example, a study by Yousef et al., (2008) [5] reported self-medication to be influenced by the high cost of health care, while lack of enforcement of legislations restricting over-the-counter sale of antibiotics was sighted as a reason for continued use of antimicrobial self-medication [11]. In addition, a recent global antimicrobial self-medication systematic review included few studies from developing countries, and excluded antimalarial self-medication [3]. Although various individual studies have examined antimicrobial self-medication in low and middle income countries, there has not been any systematic review done in this setting. There is need for evidence from well-designed studies on community use of antimicrobial drugs in these settings to help in planning and implementation of specific interventions on nonprescription antibiotic use.

We therefore performed a systematic review of observational studies to estimate the burden, risk factors and effects of antimicrobial self-medication in communities of low and middle income countries. Information on estimates of antimicrobial self-medication by geographical regions, sources of drugs, sources of drug information, clinical outcomes, antimicrobials agents and drug use practices are also summarized.

\section{Methods}

\section{Protocol development}

In 2012, we developed and registered a review protocol (\#CRD42012002508) in the International Prospective Register of Systematic Reviews that is available at: http:// www.crd.york.ac.uk/PROSPERO/. We observed the recommendations of the PRISMA statement [12] in developing this protocol and review conduct.

\section{Search strategy}

RS, a librarian with Infectious disease institute Makerere University searched PubMed, Embase, Medline, and Scopus databases to identify studies that investigated antimicrobial self-medication in communities of low and middle income countries. The following search terms were combined using Boolean operators, antimicrobial, antibiotics, antibacterial, antimalarial, self-medication, non-prescription and the time period 2002-2012. Medical Subject Headings (MeSH) of the search terms was used in each case to maintain common terms across all data bases searched. All database searches were updated in February 2014. We searched bibliographies of included studies for additional articles. There was no language restrictions applied during the search neither did we search any grey literature for additional articles.

\section{Eligibility criteria for the articles included in the review}

The review included studies on antimicrobial selfmedication among adult individuals (18 years or older) in community households of low and middle income countries. We included only studies which did not assess chronic non-prescription antimicrobial use and reported the estimate of its prevalence. We excluded studies that assessed antimicrobial self-medication among; children, pregnant/breast feeding mothers, institutionalized elderly patients, students of health related courses and health professionals. In addition editorials, letters to the editor or comment publication type were also excluded. Studies done on children below eighteen years and institutionalized elderly were excluded from the review as they do not make independent treatment decisions; while students and workers of health profession are already exposed to unique knowledge and practices about antimicrobial use. Additionally, we excluded surveys of pharmacy bulk purchases or health facility exit interviews. This is because they do not provide reliable estimates of non-prescription antibiotic use despite being recommended by WHO for monitoring drug use [7]. We also excluded self-medication studies which measured knowledge only or attitude only or beliefs only and did not determine community behavior or practices. Studies on non-prescription antibiotic use done earlier than 2002 were excluded from the review as they are more likely to be affected by the regular changes in drug polices and treatment guidelines.

\section{Assessment of risk of bias of included studies}

$\mathrm{OC}$ and EO independently assessed the risk of bias in the included studies and any disparities were resolved by discussion. We assessed the following potential sources of bias in observational studies using a tool of eight criteria that was adopted from the STROBE statement [13]. Selection bias due to sampling, selection bias due to responders or response rate (adequate if $\geq 60 \%$ ), detection bias due to recall ( $\leq 1$ month; [14], detection bias due; social desirability, reliability of measurement tools and method of analysis used to assess factors associated with antimicrobial self-medication. We contacted authors of the included articles for clarification where information was missing. Each of the risk of bias criteria was assessed as low (scored as 0), moderate/high or unclear (scored as 1). We manually computed these scores into three levels of bias with 0-2 (low risk), 3-4 (moderate risk) and 5-8 (high risk). 


\section{Data abstraction}

We developed a data abstraction spreadsheet using Excel version 2007 (Microsoft Corporation, Redmond, Washington, USA). OC and EO conducted duplicate and independent abstraction of data from the included studies. We captured the following information, author, year of publication, journal, country where the study was done, recall period, study design, sample size, response rate, prevalence of antimicrobial self-medication, type of antimicrobial agents used, source of drugs, source of drug information, disease symptoms, determinants of antimicrobial selfmedication, adverse effects, disease symptom resolution, risks associated with antimicrobial self-medication, reasons for self-medication, duration of drug use, and inappropriate drug use practices (not completing dose, sharing of drugs and short duration of use). In order to assess the determinants of antimicrobial self-medication, we considered data from only those studies that conducted multivariable regression.

\section{Data synthesis}

We exported the $\operatorname{Excel}^{\odot}$ abstraction sheet to Stata ${ }^{\circ}$ software version 12.0 (Stata Corp, College Station, Texas, USA) for analysis. We performed both structured narrative and quantitative syntheses as appropriate. In the structured synthesis we generated descriptive summaries of the outcomes of interest from the included studies for the sources of drugs and drug information, types of antimicrobials, reported clinical outcomes, drug use practices and the determinants of self-medication. In order to estimate the prevalence of antimicrobial self-medication, we recomputed the primary study measures of proportions and the corresponding standard errors taking into regard the response rate.

We performed a DerSimonian-Laird Random Effects Meta-analysis to estimate the summary measure of the prevalence of antimicrobial self-medication, using the Stata ${ }^{\odot}$ command "metaan". We displayed our findings in a forest plot and explored the high heterogeneity using the following sub - group analyses; region where the study was conducted (sub-Saharan Africa, Latin America, Middle East and Asia) as well as the levels of risk of bias (low, moderate and high) as shown in Table 2.

\section{Results}

\section{Study selection}

The search of PubMed, Embase, Medline and Scopus data bases provided a total of 4,400 citations. After adjusting for duplicates 3,572 citations remained. Of these 3,401 studies were discarded since after reviewing their titles and abstracts, they did not meet the criteria. Seven studies were discarded as their full text was not available. The full text of the remaining 171 studies was reviewed in detail. A total of 143 studies did not meet the criteria and were discarded. Thirty four (34) studies met the inclusion criteria and were included in the systematic review. Additional six studies that met the criteria for inclusion were identified through searching the reference lists of located, relevant papers and searching for the studies that had cited these papers (Fig. 1). Two reviewers OM and EO screened the studies for inclusion and exclusion in the review with a kappa agreement of $0.74(74 \%)$.

\section{Characteristics of included studies}

All the thirty four (34) studies finally selected for the review were cross-sectional observational studies published in English, French and Spanish and involved 31,340 participants. The recall period used in data collection varied among different studies, ranging from two weeks to one year (12 months). Most studies (19/34: $55.9 \%)$ reported recall period used in data collection. Of the included studies, seven (7/34: $20.6 \%$ ) used a time lag of between two -to- four weeks [15-21] (Table 1). While three studies (3/34: $8.8 \%$ ) used twelve months [22-24].

Of the 34 studies, only 7 (20.6\%) established determinants of antimicrobial self-medication using multiple regression analysis. Fifteen studies (15) were from SubSaharan Africa, eight (08) Asia, eight (08) Middle East and three (3) from South America. Nineteen (19) studies reported the recall period used during data collection. Less than one month [15-21], 2-5 months [25-29] and 6-12 months [22-24, 30-33] while fifteen studies did not report the recall period use [34-48] (Table 1).

The majority of studies, $79.1 \%$ (27/34) reported symptoms related to infections of; respiratory tract, gastrointestinal system, eye, ear, urinary system, skin and malaria as the reason for self-medication. Of the thirty four (34) studies, five (5) reported the duration of treatment using antimicrobial self-medication in management of the illness. Four-to-seven days [21] (antibiotics); one-to-three days [32] (antimalarial); three days [23] (antimalarial); and three-four days $[16,17]$ (antibiotics).

\section{Risk of bias in the included studies}

The majority of included studies (27/34: 79.4\%) did not assess determinants of antimicrobial self-medication using multivariable regression analysis. Fourteen of the included studies (14/34: $41.1 \%$ ) had low risk of bias, twelve (12/34: $35.3 \%)$ had moderate risk of bias while eight (8/34: $23.5 \%)$ had a high risk of bias.

Following the risk of bias assessment criteria used, most of the included studies had potential risk of; bias due to method of analysis used in establishing associated factors (28/34: 82.4\%), recall bias (23/30: $67.6 \%$ ), selection bias (12/34: $35.3 \%)$, detection bias due to social desirability (13/34: $38.2 \%)$, selection bias due to baseline 


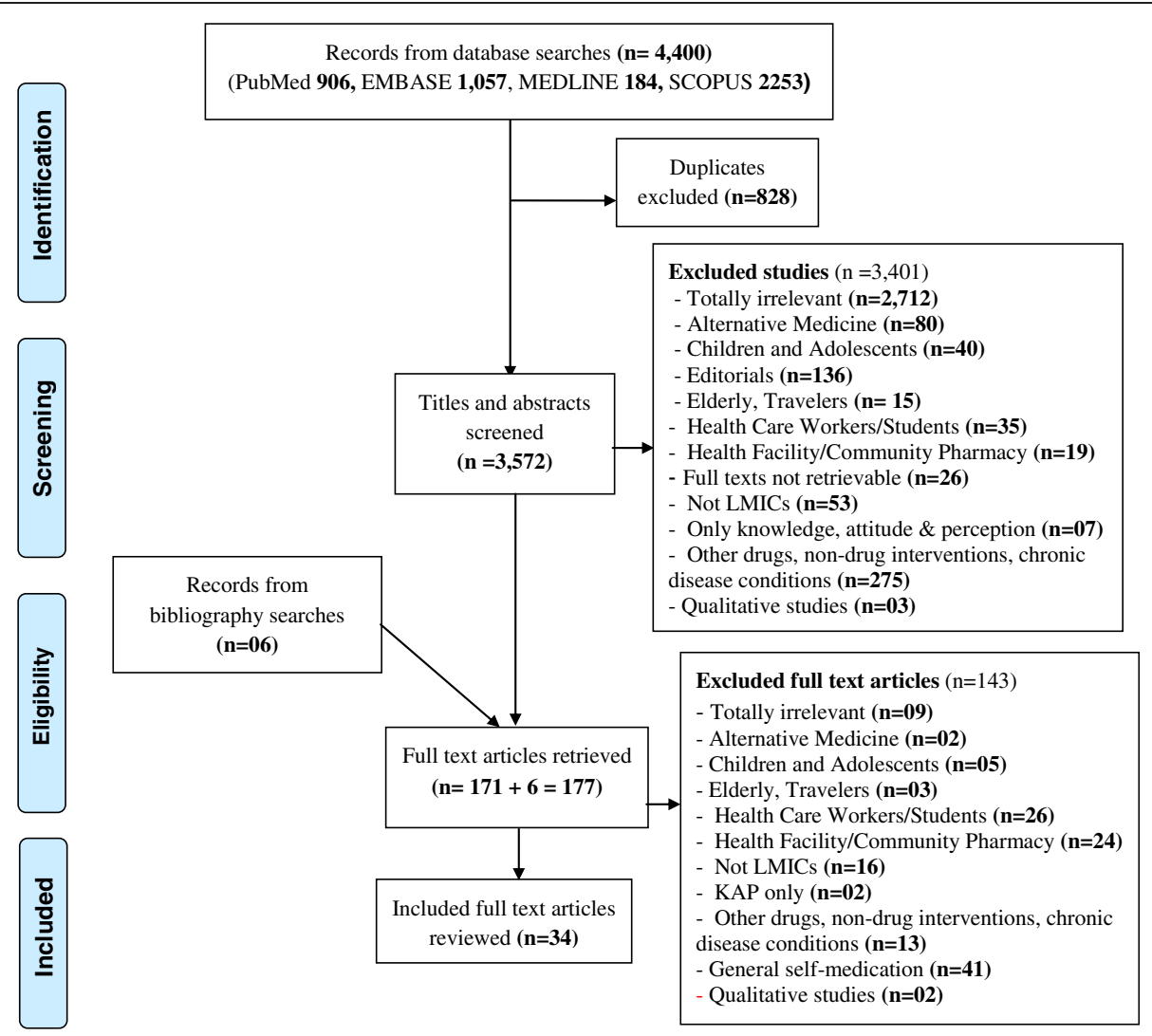

Fig. 1 Flow diagram of study selection

characteristics (17/34: $50 \%)$ and selection bias due to sampling criteria (13/34: $38.2 \%$ ) (Additional file 1: Appendix 1).

Antimicrobial medicines commonly used in self-medication The major categories of antimicrobial agents reportedly used in self-medication included antimalarial and antibacterial. Of the thirty four studies included in the review, seventeen (50\%) investigated only antibacterial drugs, eight $(23.5 \%)$ antibacterial and antimalarial drugs, five (14.7\%) antimalarial drugs only, and four (11.8\%) studied multiple antimicrobial agents used in self-medication. The antimalarial medicines commonly used in self-medication included, chloroquine, sulfadoxine-pyrimethamine, halofantrine, Artemether-Lumefantrine, and quinine. While the antibacterial agents used included; ampicillin, tetracycline, penicillin, metronidazole, ceftriaxone, kanamycin, ciprofloxacin, amoxicillin, fradiomisin-gramisidin, norfloxacin and doxycycline (Table 2).

\section{Source of medicines, information and benefits of antibiotic self-medication}

Information on antimicrobial agents used in selfmedication in developing countries is obtained from various sources. Majority of the studies reported drug sellers or pharmacists and relatives or friends. The other reported sources include; past successful use and drug leaflets. The antimicrobial drugs used in self-medication were obtained from various sources such as pharmacies, leftover drugs, hospitals, gifts from friends and drug shops.

The antimicrobial agents used in self-medication were obtained from various sources such as pharmacies, $61.8 \%$ (21/34); leftover drugs, $41.2 \%$ (14/34); gifts from friends/ relatives, $26.5 \%$ (9/34), drug shops, $23.5 \%$ (8/34) and health facilities, $26.5 \%(9 / 34)$.

The reported importance of antimicrobial selfmedication include, saving time $[19,25,32,35,41-43$, $45,46]$, avoids crowding [23], and quick relief of the illness [35].

\section{Prevalence of antimicrobial self-medication}

The prevalence of antimicrobial self-medication in low and middle income countries varied widely with some studies reporting as low as $4.0 \%$ in Yemen [34] to as high as $91.4 \%$ in Nigeria [46]. The overall estimate of antimicrobial self-medication in low and middle income countries is $38.8 \%$ (95 \% CI: 29.5-48.1). Reports from studies done in South America had a high, 44.1 \% \% (95 \% CI: $9.7 \%-78.6 \%)$ overall prevalence of antimicrobial selfmedication while the Middle East had the lowest $34.1 \%$ 
Table 1 Summary of included studies on antimicrobial self-medication in LMICs

\begin{tabular}{|c|c|c|c|c|c|c|}
\hline Study & Country & $\begin{array}{l}\text { Recall } \\
\text { period/ } \\
\text { Weeks }\end{array}$ & $\begin{array}{l}\text { Prevalence } \\
\text { of SM ( \%) }\end{array}$ & Incorrect drug use & Outcomes & Disease symptoms treated \\
\hline $\begin{array}{l}\text { Abdo-Rabbo, } \\
2003\end{array}$ & Yemen & NR & $4 \%$ & NR & NR & Fever (4 \%) \\
\hline Agbor (2011) & Cameroon & NR & $21.2 \%$ & & $\begin{array}{l}\text { Symptoms resolved } \\
\text { in a week (39.7\%) }\end{array}$ & $\begin{array}{l}\text { Tooth ache }(54.7 \%) \text {, gingival } \\
\text { bleeding }(13 \%)\end{array}$ \\
\hline Al-Azzam, 2007 & Jordan & 4 & $9.5 \%$ & NR & NR & $\begin{array}{l}\text { RTIS (39.1 \%), GIT (4.9\%), UTIS } \\
(2.9 \%) \text {, Ear (1.3\%) }\end{array}$ \\
\hline Askarian, 2012 & Iran & 52 & $43.7 \%$ & NR & NR & RTIs (73.1 \%, GIT (41 \%) \\
\hline Auta, 2012 & Nigeria & 3 & $17.9 \%$ & NR & NR & NR \\
\hline Awad, 2005 & Sudan & 4 & $73.7 \%$ & $\begin{array}{l}\text { Inadequate dose }(39 \%) \\
\text { Short duration }(39 \%)\end{array}$ & NR & RTIs (20.1 \%), fever/malaria (5.5 \%) \\
\hline Bano, 2012 & Pakistan & NR & $55 \%$ & Wrong dose, short duration & NR & $\begin{array}{l}\text { RTIs (41.3\%), fever/malaria (80 \%), } \\
\text { GIT (61.3\%), Skin (72.6\%) }\end{array}$ \\
\hline Barah, 2010 & Syria & 4 & $48.4 \%$ & $\begin{array}{l}\text { Stop taking drugs when } \\
\text { symptoms improve ( } 50 \%)\end{array}$ & $\begin{array}{l}\text { Allergies }(13 \%) \text {, failed } \\
\text { to cure }(10 \%)\end{array}$ & NR \\
\hline Chowdhury, 2009 & Bangladesh & 24 & $18.3 \%$ & $\begin{array}{l}\text { Stopped taking drugs when } \\
\text { felt better }(3.6 \%)\end{array}$ & $\begin{array}{l}\text { Symptoms resolved } \\
(2.2 \%)\end{array}$ & $\begin{array}{l}\text { Fever/malaria (55 \%), GIT (9 \%), } \\
\text { Skin (11\%) }\end{array}$ \\
\hline de Oliveira, 2004 & Brazil & NR & $10.1 \%$ & Incorrect use (0.5\%) & $\begin{array}{l}\text { Symptoms did not } \\
\text { resolve }(3.5 \%)\end{array}$ & NR \\
\hline Deressa, 2003 & Ethiopia & 24 & $17.8 \%$ & Dose not completed (4.3\%) & NR & Fever/malaria (97 \%) \\
\hline Enato, 2011 & Nigeria & 2 & $44.9 \%$ & NR & $\begin{array}{l}\text { Symptoms resolved } \\
(96 \%)\end{array}$ & Fever/malaria (57.6 \%) \\
\hline Hussain, 2011 & Pakistan & 12 & $17.8 \%$ & NR & NR & $\begin{array}{l}\text { RTIs (14.5\%), fever/malaria (57.6\%), } \\
\text { GIT (8.4 \%), Skin ( } 8.6 \%)\end{array}$ \\
\hline Jassim, 2010 & Iraq & NR & $63.5 \%$ & $\begin{array}{l}\text { Dose not completed (54\%), } \\
\text { sharing drugs }(12 \%)\end{array}$ & NR & $\begin{array}{l}\text { RTIs (11.3\%), fever/malaria (8.1\%), } \\
\text { GIT (11.3\%), Skin (4.9\%), UTIs } \\
(4.1 \%) \text {, Ear (3.6 \%) }\end{array}$ \\
\hline Jombo, 2011 & W. Africa & NR & $38.4 \%$ & NR & NR & NR \\
\hline Lima, 2010 & Brazil & NR & $69.2 \%$ & Sharing drugs & NR & RTIS, GIT \\
\hline Mossa, 2012 & Ethiopia & 12 & $14.6 \%$ & $N R$ & NR & $\begin{array}{l}\text { RTIs (14.1\%), fever/malaria (35.9\%), } \\
\text { GIT (10.2 \%) }\end{array}$ \\
\hline Nounon, 2009 & Argentina & NR & $53.1 \%$ & $\begin{array}{l}\text { Stopped taking drugs when } \\
\text { felt better (14 \%) }\end{array}$ & $\begin{array}{l}\text { Symptoms resolved } \\
(4 \%)\end{array}$ & $\begin{array}{l}\text { RTIs (48 \%), fever/malaria (18 \%), } \\
\text { Skin (1 \%), UTIs (7 \%) }\end{array}$ \\
\hline Ngasha, 2011 & Cameroon & NR & $55.7 \%$ & NR & $\begin{array}{l}\text { Symptoms did not } \\
\text { resolve }\end{array}$ & Fever/malaria \\
\hline Okumura, 2002 & Vietnam & NR & $12.7 \%$ & NR & NR & RTIs (3.1 \%), GIT (1.6 \%) \\
\hline Onanuga, 2011 & Nigeria & NR & $45 \%$ & $\begin{array}{l}\text { Not completed dose }(16.7 \%) \text {, } \\
\text { stopped taking drugs when } \\
\text { symptoms resolved ( } 28.3 \%)\end{array}$ & $\begin{array}{l}\text { Experienced adverse } \\
\text { effects }(65.8 \%)\end{array}$ & NR \\
\hline $\begin{array}{l}\text { Onohwosafe, } \\
2013\end{array}$ & Nigeria & NR & $54.8 \%$ & NR & NR & Fever/malaria (49.6\%) \\
\hline Osemene, 2012 & Nigeria & NR & $91.4 \%$ & NR & NR & $\begin{array}{l}\text { RTIs (15.3\%), fever/malaria (5.5 \%), } \\
\text { GIT (10.2 \%), UTIs (43.5\%), Ear (2 \%) }\end{array}$ \\
\hline Oyetunde, 2010 & Nigeria & NR & $25.9 \%$ & Short duration (90 \%) & NR & NR \\
\hline Omole, 2010 & Nigeria & 12 & $35.7 \%$ & NR & $\begin{array}{l}\text { Not cured }(33.7 \%) \text {, } \\
\text { cured }(12.9 \%)\end{array}$ & Fever/malaria, GIT \\
\hline Sanjana, 2006 & Indonesia & 52 & $42 \%$ & NR & $\begin{array}{l}\text { Adverse effects ( } 23 \%) \text {, } \\
\text { relapse of malaria }\end{array}$ & Fever/malaria (93 \%), GIT (17\%) \\
\hline Sapkota, 2010 & Nigeria & 12 & $25.2 \%$ & NR & NR & None specific symptoms \\
\hline Sarahroodi, 2009 & Iran & 12 & $54.5 \%$ & Not completing dose (74.2 \%) & NR & RTIs (66.7 \%), GIT (23 \%) \\
\hline Sawalha, 2008 & Palestine & 24 & $19.4 \%$ & Not completing dose (59.9\%) & NR & RTIs (30.3 \%), Ear (3.3 \%) \\
\hline
\end{tabular}


Table 1 Summary of included studies on antimicrobial self-medication in LMICs (Continued)

\begin{tabular}{|c|c|c|c|c|c|c|}
\hline Shankar, 2002 & Nepal & 24 & $59.2 \%$ & NR & NR & Fever/malaria \\
\hline Shehadeh, 2012 & Jordan & 52 & $30 \%$ & Not completing dose (38.5 \%) & $\begin{array}{l}\text { ADRs (69.6 \%), Allergy, } \\
\text { harm the teeth }\end{array}$ & RTIs (31 \%), UTIs (4.7\%), Ear (3.8 \%) \\
\hline Sihavong, 2006 & LPR & 52 & $91 \%$ & $\begin{array}{l}\text { Short duration of taking } \\
\text { drugs }(79 \%)\end{array}$ & NR & UTIs (78 \%) \\
\hline Widayati, 2011 & Indonesia & 4 & $8.1 \%$ & $\begin{array}{l}\text { Short duration of taking } \\
\text { drugs }(36.6 \%)\end{array}$ & NR & RTIs (31.8\%), fever/malaria (12.2 \%) \\
\hline Yousif, 2002 & Sudan & NR & $46.9 \%$ & $\begin{array}{l}\text { Sharing drugs (59.3\%), Not } \\
\text { completing dose }(28.8 \%)\end{array}$ & NR & NR \\
\hline
\end{tabular}

LMICs: Low and Middle Income countries, NR: Not Reported, RTIs: Respiratory Tract Infections, GIT: Gastrointestinal tract, UTIs: Urinary Tract Infections, LPR: Lao People's Republic

(95 \% CI: $23.4 \%-44.9 \%$ ) (Table 3). The overall prevalence was higher among respondents who reported using multiple medicines, 61.9 \% (95 \% CI: $53.9 \%-70.1 \%$ ), both antibacterial and antimalarial agents, $42.9 \%(95 \%$ CI: $19.6 \%-66.3 \%$ ), antibacterial agents $33.4 \%$ (95 \% CI: $20.6 \%-46.1 \%)$ and lower in studies in which participants used only antimalarial agents only $30.3 \%$ (95 \% CI: $10.1 \%-50.4 \%)$. There was high heterogeneity in the included studies $\left(\mathrm{I}^{2}=100 \%\right)$ for all the sub-groups (geographic region, risk of bias, medicine used) assessed.

\section{Inappropriate practices of antimicrobial drug use in self-medication}

The most common inappropriate practice in nonprescription use of antimicrobial agents include: short duration of treatment mostly less than five days $[16,17$, $32,44,47]$, insufficient dose of medication [17, 19, 32, 47], wrong indication (use of antibacterial drugs in treating viral infections) [17, 22], and exchange/sharing of medicines [38, 40, 48, 49].

The use of antibacterial drugs in treating viral infections was mostly reported in studies done in the Middle East [22] and Asia [17]. The agents commonly used in treating symptoms of viral infections such as flu included; ampicillin, tetracycline, metronidazole, ceftriaxone, kanamycin, cotrimoxazole $[17,22]$. Short duration of treatment $(<5$ days $)$ using antimicrobial self-medication was commonly reported in Asian studies, [16, 17]. Insufficient dose of medications used in self-medication was mostly reported in sub-Saharan African studies [19, 32] and Asia [17].

\section{Factors associated with antimicrobial self-medication in developing countries}

The commonly reported factors that determined antimicrobial self-medication included; past successful use [33], low level of education [19, 21, 26, 33, 46], female gender [33], age [21,33] and middle income [19, 21, 26, 33, 46]. Studies done in Africa reported; low level of education, severity of illness (mild-to-severe), female gender, age ( $\geq 45$ years) and middle income as determinants of antimicrobial self-medication. Similarly in the Middle East, level of education, age (18-39 years) and middle income (Table 4).

\section{Clinical outcomes of antimicrobial self-medication}

The studies included in the review reported both positive and negative outcomes of the use of antimicrobial self-medication. The negative outcomes included; allergies [18, 22], lack of cure [23, 28, 37, 44] and causing death $[22,43]$. While positive outcomes attributed to the use of antimicrobial self-medication included recovery from the illness [15, 28, 33, 35].

\section{Duration of use of antimicrobial drugs in self-medication}

Twenty nine (29/34: $85.3 \%$ ) of the included studies did not report the duration which participants spent using antibiotics during an illness episode. In a study by AlAzzam, 2007 [21], participants spent 4-7 days taking non-prescription antibacterial drugs during an illness. In studies by Deressa, 2003 and Sanjana, 2006 [23, 32] participants spent 1-3 days taking antimalarial drugs

Table 2 Characteristics of antimicrobial drugs used in self-medication

\begin{tabular}{|c|c|c|c|}
\hline $\begin{array}{l}\text { Type of } \\
\text { antimicrobial }\end{array}$ & Class of antimicrobial & Drug source & Source of information \\
\hline Antibacterial & $\begin{array}{l}\text { B-lactam, Tetracycline, fluoroquinolone, macrolide, } \\
\text { quinolone, aminoglycoside, others }\end{array}$ & $\begin{array}{l}\text { leftover, pharmacy, drug shop, } \\
\text { friends/relatives }\end{array}$ & $\begin{array}{l}\text { drug seller, self, drug leaflet, past } \\
\text { prescription, friends }\end{array}$ \\
\hline Antimalarial & $\begin{array}{l}\text { Artemisinins, 4-aminoquinolines, 8-aminoquinlines } \\
\text { Cinchona alkaloid Sulfonamides/sulfone Diaminopyrimidine }\end{array}$ & pharmacy, leftover, friends/relatives & $\begin{array}{l}\text { past prescriptions, self, drug seller, } \\
\text { friends }\end{array}$ \\
\hline Antifungal & Azoles & pharmacy, leftover & drug seller, self \\
\hline Anthelmintic & Imidazole & pharmacy, leftover & $\begin{array}{l}\text { drug seller, self, past prescription, } \\
\text { friends }\end{array}$ \\
\hline
\end{tabular}


Table 3 Pooled results for the prevalence of self-medication by region, antibiotic used and condition treated

\begin{tabular}{|c|c|c|c|c|c|}
\hline Category & Description & Number of studies $(n=34)$ & Number of respondents & Prevalence of SM & $95 \% \mathrm{Cl}$ \\
\hline \multirow[t]{4}{*}{ Geographic region } & Sub-Saharan Africa & 15 & 11667 & $40.6 \%$ & $25.8-55.8$ \\
\hline & Asia & 8 & 6980 & $38 \%$ & 15.2.60.8 \\
\hline & Middle East & 8 & 11942 & $34.1 \%$ & $23.4-44.8$ \\
\hline & South America & 3 & 751 & $44.1 \%$ & $9.7-78.6$ \\
\hline \multirow[t]{3}{*}{ Risk of bias } & Low & 14 & 25009 & $39.2 \%$ & $21.6-56.9$ \\
\hline & Moderate & 12 & 3331 & $39.1 \%$ & $31.2-46.9$ \\
\hline & High & 8 & 1131 & $37.6 \%$ & $22.3-52.8$ \\
\hline \multirow[t]{4}{*}{ Medicine used } & Antibacterial only & 17 & 8486 & $33.4 \%$ & $20.6-46.1$ \\
\hline & Antimalarial only & 5 & 2411 & $30.3 \%$ & $10.1-50.4$ \\
\hline & Antibacterial and Antimalarial & 8 & 10818 & $42.9 \%$ & $19.6-66.8$ \\
\hline & Multiple antimicrobial agents & 4 & 735 & $61.9 \%$ & $53.9-70.1$ \\
\hline
\end{tabular}

SM: Self-medication, \%: Percentage, Cl: Confidence Interval

(Sulphadoxine-Pyrimethamine, chloroquine). Other studies $[16,17]$, reported participants spending less than five days taking non-prescription antibacterial drugs during an illness episode.

\section{Discussion}

\section{Main findings}

Community drug sellers often do not have adequate biomedical knowledge of the antimicrobial agents and the disease processes. However they are commonly used as source of advice or information for the antimicrobial agents obtained and used over-the-counter. Settings in which individuals are highly educated tend to have relatively low levels of use of antimicrobial self-medication. Therefore promotion of literacy among communities is an important target to minimize antimicrobial selfmedication in LMICs. Due to their prior successful use of antimicrobial agents, individuals in most communities tend to believe that they are able to manage subsequent illness without consulting a physician. This is a potential risk factor for inappropriate drug use since most patients lack knowledge of the disease process and the medicines used in self-medication. In the review, adverse effects of antimicrobial self-medication were rarely reported in the articles from most studies in LMICs.

Responsible self-medication has the potential of being an important alternative to the formal healthcare system, providing patients the opportunity of accessing immediate healthcare [50]. However in most communities especially of developing countries, in addition to accessing medicines designated as over-the-counter, individuals also use prescription only medicines without any medical supervision. Such a practice is not likely to benefit patients especially in the case of antibiotics as it's associated with potential risks to both the patient and community. The reason (s) why individuals decide to use medicines designated as prescription only without any guidance from a health professional are unique to different settings and are reflective of

Table 4 Factors that determine antimicrobial self-medication

\begin{tabular}{|c|c|c|c|c|}
\hline Region & $\begin{array}{l}\text { Number of } \\
\text { studies }\end{array}$ & $\begin{array}{l}\text { Studies with Multivariable } \\
\text { regression analysis }\end{array}$ & $\begin{array}{l}\text { Number of } \\
\text { respondents }\end{array}$ & Determinants of antimicrobial Self-medication \\
\hline \multirow[t]{6}{*}{ Africa } & \multirow[t]{6}{*}{$3 / 15$} & \multirow[t]{3}{*}{ Sapkota, 2010} & \multirow[t]{3}{*}{706} & Lower lever of education (OR: 2.8, 95 \% Cl: 1.1-7.1, $\mathrm{P}=0.03$ ) \\
\hline & & & & Non-science qualification (OR: 1.58, 95 \% Cl: 1.03-2.2.5, P = 0.04) \\
\hline & & & & Severity of illness (mild to moderate) (OR: 1.64, $95 \% \mathrm{Cl}: 1.01-2.67, \mathrm{P}=0.05)$ \\
\hline & & \multirow[t]{2}{*}{ Osemene, 2012} & \multirow[t]{2}{*}{2000} & Age ( $\geq 45$ years) (OR: $3.4, P=0.001)$ \\
\hline & & & & Female gender (OR: 3.8, $\mathrm{P}=0.001)$ \\
\hline & & Awad, 2005 & 1750 & Female gender (OR: 1.8, 95 \% Cl: 1.4-2.4 \\
\hline${ }^{\mathrm{a}}$ Asia & $0 / 8$ & None & None & None \\
\hline \multirow[t]{3}{*}{ Middle East } & \multirow[t]{3}{*}{$1 / 8$} & \multirow[t]{3}{*}{ Al-Azzam, 2007} & \multirow[t]{3}{*}{8864} & Age (18-39 years) (OR: 1.59, $95 \%$ Cl: 1.3-1.95, $\mathrm{P}<0.05)$ \\
\hline & & & & Education (primary) (OR: 2.1, 95 \% Cl: 1.09-2.08, P < 0.013) \\
\hline & & & & Income status (middle) (OR: 1.48, 95 \% Cl: 1.18-1.85, P = 0.001) \\
\hline as. America & $0 / 3$ & None & None & None \\
\hline
\end{tabular}

${ }^{a}$ No single study done in South America or Asia performed multivariable regression analysis to establish determinants of antimicrobial self-medication 
a matrix of health system, societal, economic and health factors [11]. Therefore establishing these factors is a critical step in designing and implementation of interventions against irresponsible self-medication. The current review also presents estimate of the prevalence of antibiotic selfmedication and the associated clinical outcomes in communities of LMICs.

In this review, the prevalence of antimicrobial selfmedication in LMICs was $38.8 \%$ and is consistent with the findings (39\%) of a previous review on global antimicrobial self-medication [3]. The use of antibiotics without a prescription occurs globally despite their prescription only legal status in most countries [3]. Our review revealed that the prevalence of non-prescription antibiotic use in LMICs is similar to the global rate. However the high levels of poverty as individuals cannot afford full antibiotic course and illiteracy potentially increase the likelihood of risks associated with nonprescription antibiotic use in LMICs [19]. For example development of antibiotic resistance, a consequence of inappropriate drug use commonly associated with selfmedication causes higher mortality in LMICs compared to the developed nations [51]. Our review also showed that the prevalence of antibiotic self-medication varied in different regions. This could be due to the difference in the effectiveness of enforcement of regulations on antibiotic self-medication in different resource limited countries. However, there was significant heterogeneity in the outcome of studies included in the review even after we performed sub-group analysis (region and risk of bias). Therefore we could not combine the included studies in a meta-analysis.

Self-medication has potential benefits which are shared among patients, healthcare professionals, healthcare system, and the pharmaceutical industry. For the industry; increased access to the products results in more profits; health professionals avoid unnecessary consultations with patients having minor symptoms; healthcare costs to government are reduced as individuals meet their healthcare bills and patients gain greater empowerment thus improving patient-clinician relationship [10]. A study included in this review reported rapid resolution of disease symptoms among participants [52]. Others showed that using antimicrobial self-medication, saves time, is affordable, and convenient. These positive attributes of self-medication, further reinforce community use of antimicrobial selfmedication in management of prevalent illnesses. However, it should be noted that the potential benefits associated with self-medication will only be achieved if it's done responsibly and the medicines used are safe, efficacious and information leading to their safe use is easily accessible to the communities [11].

The underlying challenges of health systems in most LMICs such as inadequate healthcare potentially influence use of self-medication [11]. In addition, the lack of policies or their inadequate implementation enables easy over-thecounter access of antibiotics [53]. A previous study in northern Uganda found that over half (59.3\%) of community members who practiced antimicrobial self-medication were not aware of any restrictions on their nonprescription use in the country [54]. This occurs in spite of the existence of national drug policy formulated in 2002 which limits antibiotics to prescription only use. Furthermore, most LMICs face the challenge of irregular supply of drugs to the public health facilities which limits community access to healthcare. This coupled with the high burden of infectious diseases in these countries makes the private sector an important alternative source of healthcare [6]. However, the profit oriented nature of service delivery in this sector in addition to the inadequate supervision, influence over-the-counter sale of antibiotics despite their prescription only legal status. The question facing most LMICs who suffer high burden of infectious diseases is how to balance improved access to antibiotics for individuals with true infectious diseases through self-medication while at the same time ensuring appropriate use.

The key determinants of antimicrobial self-medication in LMICs included; severity of illness, economic status, past successful use and educational level. Most community members do not visit a health professional prior to initiating treatment due to the associated costs such as time, travel expenses and consultation charges [55]. The high level of poverty in communities of most LMICs in addition to the fact that patients can purchase antibiotics over-thecounter using any amount of money influence antibiotic use practices [11]. The prevalent belief in self-efficacy among patients due to past illness experiences further impacts on the use of antibiotic self-medication. Community members with a high level of education were more likely to use antimicrobial self-medicate possibly due to the exposure and increased awareness on health [56]. Patients who assessed the symptoms of their illnesses as mild or moderate were more likely not to consult a healthcare professional. However, lack of biomedical knowledge of the disease symptoms is likely to increase the risk of inappropriate antibiotic use practices such as stopping treatment when symptoms resolve [11], delay in seeking appropriate treatment which may potentially result in more severe disease. Delay in seeking medical care has been associated with increased mortality among patients suffering from treatable infections such as malaria [57]. The decision by individuals in communities to use self-medication is as a result of complex interaction of various factors such as quality of healthcare, regulatory environment, burden of disease, economic factors and belief [11]. Therefore interventions to mitigate antibiotic self-medication especially in LMICs need to specifically focus on these primary factors. 
The review established inappropriate practices in antibiotic self-medication in communities of LMICs. These included, not completing dose, sharing drugs, stopping use of drugs when symptoms improve and inaccurate indication. The use of antibacterial agents in treatment of common cold was reported in studies done in Jordan [21], Iran [24], Palestine [30], Vietnam [43], and Sudan [19]. Not completing the dose of antibiotics carries a risk of clinical failure. Previous studies done in children with mild pneumonia using 3 day and 5 day amoxicillin found non-compliance as the main reason for treatment failure $[58,59]$. The majority of studies included in the review reported self-medication using multiple antimicrobial agents. The use of more than one antibiotic during an illness episode is indicative of the uncertainty of the cause of illness. These inappropriate practices potentially increase the risk of mistreatment, adverse drug reactions, resistance development and drug interactions [6, 7, 10]. This is further worsened by the high burden of infectious diseases in addition to the limited therapeutic choices in most LMICs [6]. Antibiotic resistance is likely to add further financial strain to the healthcare system which is already faced with the challenge of inadequate funding. This is especially the case as patients with resistant infections are likely to stay longer in hospitals and the need to use more expensive second line antibiotic drugs. Agencies such as World Health Organization (WHO), World Selfmedication Industry (WSMI) and the ministries of health of LMICs need to establish specific interventions focusing on these common inappropriate antibiotic use practices.

The review found that drug sellers, previous successful use, drug leaflets, past prescriptions and friends or relatives were the main sources of drug information in selfmedication. Drug leaflets are an important source of information, however poor readability makes using them challenging to use [6]. In addition, the high level of illiteracy in LMICs further limits the effectiveness of leaflets as a source of information. Providing this information in indigenous languages in addition to well written information could improve the usefulness of drug leaflets in these settings [6]. Prescription practices of physicians in communities are likely to influence antibiotic use behavior of the local population as patients commonly refer to old prescriptions in choosing medicines used in self-medication [11]. Interventions such as retention of prescriptions in the pharmacy could help mitigate use of old prescriptions in making treatment decisions in communities [60]. Drug sellers in most of the developing countries have less impetuous of knowing biomedical information of the drugs they sell as they assume that patients know what they want and for them they know the price [50]. In Lao People's Republic, over half (59 \%) of drug dispensers are not knowledgeable about the drugs that they were selling [61]. However, in this review drug sellers were frequently reported as a source of information for antibiotics obtained over-thecounter despite their potential lack of biomedical knowledge of these drugs. This increases the risk of misinforming their clients on the antibiotic agents accessed over-the-counter. Non-prescription use of antibiotics without relevant information on how to take them, indications, adverse effects and contraindications could potentially expose patients to the risk of inappropriate drug use [62] Health personnel in communities of LMICs are thus an important target for sensitization, monitoring and support supervision.

The review had some limitations, variation in the techniques of data collection and reporting in the primary studies which were included. There was a potential of bias in the included studies due to; method of analysis, recall, selection and social desirability. This invariably has an effect on the findings of the primary studies. For example, majority of studies used recall period of more than six months while others did not report the duration of recall used during data collection. In a previous study [63], it was found that a recall period of more than one month was significantly associated with the risk of recall bias. The use of non-random methods in participant recruitment in addition to not validating the data collection tools was common in most surveys and could potentially have an effect on the study outcomes. There was high heterogeneity in the studies reviewed possibly due to lack of standardized criteria of survey data collection. We were unable to access some articles during the study selection in spite of all the efforts taken. The studies included in the review rarely reported on the negative outcomes of antibiotic self-medication experienced by community members. This could be due to limited knowledge of the antibiotic medicines that they used in self-medication [34].

\section{Conclusions}

Antimicrobial self-medication is highly prevalent in resource limited countries and is commonly associated with inappropriate use. Although self-medication is an important alternative to the formal health sector especially in most LMICs, it is imperative that decisions to use nonprescription antimicrobial agents are both safe and appropriate if the potential benefits are to be maximized with minimal risks. Educational interventions targeting both health personnel and community members in addition to improving access to quality of public healthcare, enforcement of regulations on non-prescription medicine use, and reducing the burden of infectious diseases could help mitigate the challenge of non-prescription antibiotic use in LMICs. The practice of referring to old prescriptions and past successful treatment experiences by the communities is key areas of focus for the interventions. There is 
an urgent need to development and validate a method for collecting data on community antimicrobial use to help improve the quality of evidence from such survey studies.

\section{Additional file}

Additional file 1: Appendix 1. Table S5: Risk of bias assessment of included studies.

\section{Competing interests}

The authors declare that they have no competing interests.

\section{Author contributions}

The following authors participated in various ways in developing the idea into a concept $(\mathrm{MO}, \mathrm{CO}, \mathrm{JOO})$, writing the initial protocol $(\mathrm{MO}, \mathrm{EAO})$, developing the search strategy $(\mathrm{MO}, \mathrm{RS})$, identifying, selecting and appraising the included studies $(\mathrm{MO}, \mathrm{EAO}, \mathrm{DA})$, drafting the manuscript $(\mathrm{MO})$, reviewing and approving the final version of the manuscript (EAO, DA, RS, FB, JOO, CO).

\section{Acknowledgement}

$\mathrm{MO}$ is a doctoral fellow at the College of Health Sciences, Makerere University, Uganda. He is funded to study antimicrobial self-medication in low and middle income countries, by the Medical Education Partnership Initiative - Medical Education for Equitable Services for All Ugandans (MEPI-MESAU) partnership (grant number: 5R24TW008886), National Institutes of Health, Department of Human Health and Services, USA.

This systematic review has been supported by the Africa Centre for Systematic Reviews and Knowledge Translation at Makerere University College of Health Sciences, Uganda. This Centre has received funding from the International Development Research Centre (IDRC), Canada (grant number: 1072737-001); to build capacity for systematic review conduct among scientists and decision makers in East Africa. The funders had no role in study design, data collection and analysis, decision to publish, or preparation of the manuscript.

\section{Author details}

'Department of Pharmacology \& Therapeutics, College of Health Sciences, Makerere University, P.O. Box 7072, Kampala, Uganda. ${ }^{2}$ Africa Centre for Systematic Reviews and Knowledge Translation, College of Health Sciences, Makerere University, P. O. Box 7072, Kampala, Uganda. ${ }^{3}$ Department of Microbiology, College of Health Sciences, Makerere University, P.O Box 7072 Kampala, Uganda. ${ }^{4}$ Department of Psychiatry, College of Health Sciences, Makerere University, P.O Box 7072, Kampala, Uganda. ${ }^{5}$ Infectious Disease Institute, College of Health Sciences, Makerere University, P.O Box 22418, Kampala, Uganda. ${ }^{6}$ Faculty of Epidemiology and Population Health, London School of Hygiene and Tropical Medicine, London WC1E 7HT, UK

Received: 12 April 2015 Accepted: 29 July 2015

Published online: 01 August 2015

\section{References}

1. World Health Organization. Guidelines for the regulatory assessment of Medicinal Products for use in self-medication. In., vol. WHO/EDM/QSM/00.1. Geneva, Switzerland: WHO; 2000. http://apps.who.int/medicinedocs/en/d/ Jh1462e/6.htm|\#Jh1462e.6.1. Accessed on 22 June 2015

2. Cars O, Nordberg P. Antibiotic resistance -The faceless threat. Int J Risk Saf Med. 2005;17:103-10.

3. Morgan DJ, Okeke IN, Laxminarayan R, Perencevich EN, Weisenberg S. Non-prescription antimicrobial use worldwide: A systematic review. Lancet Infect Dis. 2011;11:692-701.

4. Esimone CO, Nworu CS, Obina PU. Utilization of Antimicrobial agents with and without prescriptions by Out-patients in selected pharmacies in south-eastern Nigeria. Pharm World Sci. 2007;29:655-60

5. Yousef AM, Al-Bakri AG, Bustajani Y, Wazaify M. Self-medication patterns in Amman, Jordan. Pharm World Sci. 2008;30(1):24-30.

6. Okeke IN, Klugman KP, Bhutta ZA. Antimicrobial resistance in developing countries Part II: strategies for containment. Lancet Infect Dis. 2005;5:568-80.

7. World Health Organization. Community-Based Surveillance of Antimicrobial use and Resistance in Resource constrained settings. A report on five pilot projects. Geneva, Switzerland: WHO; 2009. www.apps.who.int/ medicinedocs/documents/s16168e.pdf. Accessed on 22/June 2015.

8. Mehta U, Durrheim DN, Blumberg L, Donohue S, Hansford F, Mabuza A, et al. Malaria deaths as sentinel events to monitor healthcare delivery and antimalarial drug safety. Trop Med Int Healthsss. 2007;12(5):617-28.

9. Skliros E, Panagiotis M, Athanasia P, Aristofanis G, Matzouranis G. Selfmedication with antibiotics in rural population in Greece: A cross-sectional multicenter study. BMC Fam Pract. 2010;8:1-58.

10. Hughes CM, McElnay JC, Fleming GF. Benefits and Risks of Self-medication. Drug Safety. 2001;24(14):1027-37.

11. Radyowijati A, Haak H. Improving antibiotic use in low-income countries: an overview of evidence on determinants. Soc Sci Med. 2003;57:733-44.

12. Liberati A, Altman DG, Tetzlaff J, Mulrow C, Gotzsche PC, Loannidis JPA, et al. The PRISMA Statement for Reporting Systematic Reviews and Meta-analysis of Studies the Evaluate Healthcare Interentions: Explanation and Elaboration. PLoS Med. 2009;6(7), e1000100.

13. Vandenbroucke JP, Von Elm E, Altman DG, Gotzsche PC, Mulrow CD, Pocock SJ, Poole C, Schlesselman JJ, Egger M. Strengthening the Reporting of Observational Studies in Epidemiology (STROBE): Explanation and elaboration. Int J Surg. 2014, xxx:1-25 (Article in Press).

14. Ansah EK, Powell-Jackson T. Can we trust measures of healthcare utilization from household surveys? BMC Public Health. 2013;13:853.

15. Enato EF, Sounyo AA, Einarson TR. Medication utilization and illness management study in Nigeria. Ann Pharmacother. 2011;45:924-30.

16. Widayati A, Suryawati S, Charlottee C, Hiller J. Self-medication with antibiotics in Yogyakarta City Indonesia: A cross-sectional population-based survey. BMC Research Notes. 2011:4:491.

17. Sihavong A, Lundborg CS, Syhakhang LAK, Tomson G, Wahlstrom R. Antimicrobial self-medication for reproductive tract infection in two provinces in Lao Peoples' Democratic Republic. Sex Transm Infect. 2009;82:182-6

18. Barah F, Gonclaves V. Antibiotic use and knowledge in the community in Kalamoon, Syrian Arab Republic: a cross-sectional study. EMHJ. 2010;16(5):516-21.

19. Awad A, Eltayeb I, Matowe L, Thalib L. Self-medication with antibiotics and antimalarials in the community of Khartoum state, Sudan. J Pharm Pharmaceut Sci. 2005;8(2):326-31.

20. Auta A, Banwat SB, Dayom DW, Shalkur D, Aru MO. Occurance and treatment of common health problems in a Nigerian community. J Young Pharm. 2012:4(1):49-53.

21. Al-Azzam SI, Al-Husein BA, Alzoubi F, Masadeh MM, Al-horani S. Selfmedicaiton with antibiotics in Jordanian Population. IJOMEH. 2007;20(4):373-80

22. Shehadeh M, Suaifan G, Darwish RM, Wazaify M, Zaru L, Alja'fari S. Knowledge, attitudes and behavior regarding antibiotics use and misuse among adults in the community of Jordan. A pilot study. Saudi Pharm J. 2012;20:125-33.

23. Sanjana P, Barans MJ, Bangs MJ, Ompusunggu S, Elyazar I, Marwoto $H$, et al. Survey of community knowledge, attitudes and practices during a malaria epidemic in central Java, Indonesia. Am J Trop Med Hyg. 2006;75(5):783-9.

24. Askarian M, Maharlouie N. Irrational Antibiotic use among secondary school teachers and university faculty members in Shiraz, Iran. Int J Prev Med. 2012;3(12):839-45

25. Mossa DA, Wabe NT, Angamo MT. Self-medication with antibiotics and antimalarials in the community of Silte zone, South Ethiopia. TAF Preventive medicine Bulletin. 2012:11(5):529-36.

26. Sapkota AR, Coker ME, Goldstein RE, Atkinson NL, Sweet SJ, Sopeju PO. Self medication with antibiotics for the treatment of menstrual symptoms in south west Nigeria: a cross-sectional study. BMC Public Health. 2010;10:610.

27. Sarahroodi S, Arzi A. Self-medication with Antibiotics, Is it a problem among Iranian College Students in Tehran? J Biol Sci. 2009;9(8):829-32.

28. Omole MK, Onademuren OT. A survey of antimalarial drug use practices among urban dwellers in Abeokuta, Nigeria. Afr J Biomed Res. 2010;13:1-7.

29. Hussain S, Malik F, Hameed A, Riaz H. Exploring Health seeking behavior, Medicine use and self-medication in rural and urban Parkistan. Southern Med Rev. 2010:3:32-4.

30. Sawalha AF. Self-medication with antibiotics: A study in Palestine. Int J Risk Safety Med. 2008;20:213-22.

31. Shankar PR, Partha P, Shenoy N. Self-medication and non-doctor prescription practices in Pokhara valley, Western Nepal: a questionnaire-based study. BMC Fam Pract. 2002:3:1-7. 
32. Deressa W, Ali A, Enqusellassie F. Self-treatment of malaria in rural communities, Butajira Southern Ethiopia. Bull World Health Organ. 2003;81:261-8

33. Chowdhury N, Matin F, Chowdhury SKFUA. Medication taking behavior of students attending a private university in Bangladesh. Int J Adolesc Med Health. 2009;21(3):361-70.

34. Abdo-Rabbo A. Household survey of treatment of malaria in Hajjah, Yemen. East Mediterr Health J. 2003:9(14):600-6.

35. Agbor MA, Azodo CC. Self-medication for oral health problems in Cameroon. Int Dent J. 2011:61:204-9.

36. Bano N, Najan R, Qazi F. Irrational drug use based on self-medication for some common clinical conditions in an educated population of Karachi. Pak J Med Sci. 2012;28(3):359-62.

37. de Oliveira CM, Buzzatto W, Garcia R, Baracho CNV, Arango HG: Survey of the occurrence of self-medication in the Municipality of Itajuba-MG. 2004.

38. Jassim A. In-home drug storage and self-medication with antimicrobial drugs in Basrah, Iraq. Oman Med J. 2010;25(2):1-9.

39. Jombo GTA, Araoye MA, Damen JG. Malaria self-medication and choices of drugs for its treatment among residents of a malaria endemic community in Western Africa. Asian Pac J Trop Dis. 2011;10:16.

40. Lima GB, Nunes LCC, de Barros JA C. The use of medicines storage in the household in a population assisted by Family Health Program. Sci Public Health. 2010;15 Suppl 3:3517-22.

41. Nounou B, Cattaneo ME, Salmon R, Palasezze L, Boccaleri J, Cestona E, et al. A study regarding consumption and self-medication with antibiotics in the city of Laplata (Buenos Aires, Argentina). Lat Am J Pharm. 2009;28(4):544-51.

42. Ngasha DS, Njunda AL, Kamga HLF, Ngasha SM, Assob JCN, Wlysonge CS, et al. Knowledge and practices relating to malaria in a semi-urban area of Camerron: Choices and sources of antimalarials, self-medication and resistance. Pan Afr Med J. 2011:9:8.

43. Okumura J, Wakai S, Umenai T. Drug utilization and self-medication in rural communities in Vietnam. Soc Sci Med. 2002;54:1875-86.

44. Onanuga A, Temedie TC. Multidrug-resistant intestinal Staphylococcus aureus among self-medicated Healthy Adults in Amassoma, South-South Nigeria. J Health Popul Nutr. 2011;29(5):446-53.

45. Onohwosafe PS, Olaseha IO. Factors influencing self-medication among students of Abadina College, Ibadan, Nigeria. Int J Health Promot Educ. 2013:42(1):27-32.

46. Osemene KP, Lamikanra A. A study of the prevalence of self-medication practice among university students in Southwestern Nigeria. Trop J Pharmaceut Res. 2012;11(4):683-9.

47. Oyetunde OO, Olugbake OA, Famudehin KF. Evaluation of use of antibiotics without prescription among young adults. Afr J Pharm Pharmacol. 2010:4(10):760-2.

48. Yousif MA. In-home storage and utilization habits: a Sudanese study. East Mediterr Health J. 2002;8(2/3):422-31.

49. Sharif SI, Abduelkarem AR, Bustami HA, Haddad LI, Khalil DS. Trends of home drug storage and use in different regions across the northern United Arab Emirates. Med Princ Pract. 2009;19:355-8.

50. Bennadi D. Self-medication: A current challenge. J Basic Clin Pharma. 2014;5:19-23.

51. Nickerson EK, Hongsuwan M, Limmathurotsakul D, Wuthiekanun V, Shah KR, Srisomang P. Staphylococcus aureus bacteraemia in a tropical setting: patient outcome and impact of antibiotic resistance. PLoS One. 2009;4, e4308.

52. Balamurugan E, Ganesh K. Prevalence and Pattern of self-medication use in coastal regions of South India. BJMP. 2011;4(3):a428.

53. World Health Organization. The World Medicines Situation. Geneva, Switzerland: WHO; 2011. http://www.who.int/medicines/areas/policy/ world_medicines_situation/WMS_ch6_wPricing_v6.pdf. Accessed on 22 June 2015.

54. Ocan M, Bwanga F, Bbosa GS, Bagenda D, Waako P, Ogwal-Okeng J, et al. Patterns and Predictors of self-medication in Northern Uganda. PLOS ONE. 2014;9(3), e92323.

55. Chang F, Trivedi PK. Economics of Self-medication: Theory and evidence. Health Economics. 2003;12:721-39.

56. Martins AP, Miranda AC, Mendes Z, Soares MA, Ferreira P, Nogueria A Self-medication in a Portuguese urban population: a prevalence study. Pharmacoepidemial Drug Saf. 2002;11:409-14.

57. Ibrahim EH, Sherman G, Ward S, Fraser VJ, Kollef MH. The influence of inadequate antimicrobial treatment of blood stream infections on patient outcomes in the ICU setting. Chest. 2000;118:146-55.
58. Agarwal G, Awasthi S, Kabra SK, Kaul A, Singhi S, Walter SD. Three day versus five day treatment with amoxicillin for non-severe pneumonia in young children: a multicenter randomized controlled trial. BMJ. 2004;328:791.

59. Pakistan Multicenter Amoxycillin Short Course Therapy (MASCOT) pneumonia study group. Clinical efficacy of 3 days versus 5 days of oral amoxicillin for treatment of childhood pneumonia: a multicenter double-blind trial. Lancet. 2002;360:835-42.

60. Santa-Ana-Tellez Y, Mantel-Teeuwisse AK, Dreser A, Leufkens HGM, Wirtz VJ. Impact of over-the-counter restrictions on antibiotic consumption in Brazil and Mexico. PLoS ONE. 2013;8(10), e75550.

61. Stenson B, Syhakhang L, Eriksson B, Tomson G. Real World Pharmacy: assessing the quality of private pharmacy practice in the Lao People's Democratic Republic. Soc Sci Med. 2001;52(3):393-404.

62. Shehnaz SI, Khan N, Streedharan J. Self-medication and related health complaints among expatriate high school students: A cross-sectional survey in the United Arab Emirates. Pharm Pract. 2013;11:211e218.

63. Arnold BF, Gallani S, Ram PK, Hubbard AE, Briceno B, Gertler PJ, et al. Optimal recall period for care-giver reported illness in risk factor and intervention studies: A multi-country study. AM J Epidemiol. 2013;177(4):361-70.

\section{Submit your next manuscript to BioMed Central and take full advantage of:}

- Convenient online submission

- Thorough peer review

- No space constraints or color figure charges

- Immediate publication on acceptance

- Inclusion in PubMed, CAS, Scopus and Google Scholar

- Research which is freely available for redistribution 